Tạp chí Khoa học và Công nghệ biển T12 (2012). Số 1. Tr 17 - 26

\title{
CHƯƠNG TRÌNH MÁY TÍNH XÁC ĐỊNH XU HƯỚNG DI CHUYỂN TRẦM TÍCH VÀ ÁP DỤNG THỬ NGHIỆM Ở VÙNG BIỂN VEN BỜ HẢI PHÒNG - QUẢNG NINH
}

\author{
NGUYẼ̃N NGỌC ANH \\ Viện Tài nguyên và Môi trường biển, Hải Phòng \\ NGUYỄN VĂN VƯợNG \\ Trường Đại học Khoa học Tụ̣ Nhiên, ĐHQG Hà Nội
}

\begin{abstract}
Tóm tắt: Các thông số kich thước hạt trầm tích luôn biến đổi trong các môi trường trầm tích khác nhau nhu môi truờng sông, bãi biển, sa mạc v.v. Tuy nhiên, sự biến đổi theo không gian của các thông số đó cũng diê̂n ra trong cùng một môi trưòng trầm tích, tuoong ứng với hướng di chuyển trầm tích. McLaren và Bowles đã chỉ ra rằng các thông số kích thước hạt trầm tích có thể xác định được huơơng di chuyển trầm tích. Nghiên cưu này ghi nhận một chuoong trình máy tính xác định huớng di chuyển trầm tích dụa trên phuơng pháp của McLaren và Bowles. Chưong trình máy tính trên được viết bằng ngôn ngũ lập trình fortran và có thể chạy trên các máy tính sử dụng hệ điều hành Window. Kết quả tính toán tù chuoong trình có ý nghĩa quan trọng trong các nghiên cứu trầm tích luận, đặc biệt là khôi phục chế độ thạch động lực của môi truờng tích tụ trầm tích.
\end{abstract}

\section{MỞ ĐẦU}

Các thông số kích thước hạt trầm tích luôn biến đổi trong các môi trường trầm tích khác nhau như môi trường sông, bãi biển, biển khơi và sa mạc. Tuy nhiên, sự biến đổi các thông số kích thước hạt trầm tích theo không gian cũng diễn ra trong cùng một môi trường tích tụ trầm tích tương ứng với hướng di chuyển trầm tích. Russell [10] đã xác định được ba cơ chế biến đổi kích thước hạt trầm tích bao gồm mài mòn kích thước hạt trầm tích, chọn lọc hay phân dị trầm tích trong quá trình di chuyển và hỗn hợp của các trầm tích có nguồn gốc khác nhau. Vì vậy, nghiên cứu mối liên hệ giữa biến đổi kích thước hạt trầm tích và sự di chuyển của nó đã mở ra khả năng suy ra hướng di chuyển trầm tích $[2,3,4$, $6,7,8,9,10,13,14]$. Kết quả nghiên cứu của McLaren [7] và McLaren and Bowles [8] đã chỉ ra rằng các thông số kích thước hạt trầm tích như đường kính hạt trung bình, độ chọn lọc và độ bất đối xứng có thể xác định được xu hướng di chuyển trầm tích. Hiện nay, mô hình McLaren and Bowles vẫn được các nhà trầm tích luận sử dụng rộng rãi bởi đó là một 
mô hình đơn giản, cho phép tính toán nhanh và phản ánh được lịch sử tích tụ trầm tích đã diễn ra trong quá khứ. Mục đích của bài báo này là giới thiệu một chương trình máy tính xác định hướng di chuyển trầm tích sử dụng phương pháp McLaren, đồng thời cũng đưa ra một số ví dụ áp dụng chương trình máy tính trên cho khu vực biển nông ven bờ Hải Phòng - Quảng Ninh.

\section{PHƯONG PHÁP}

Xu hướng di chuyển trầm tích trong mô hình McLaren [8] được xác định thông qua việc so sánh kích thước hạt trung bình, độ chọn lọc và độ bất đối xứng của các mẫu trầm tích theo một tuyến mặt cắt nhất định. Với $n$ mẫu trầm tích cho trước thì sẽ có $n(n-1) / 2$ cặp mẫu phản ánh hướng di chuyển trầm tích được đề nghị. Khi so sánh hai mẫu trầm tích bất kỳ với nhau thì sẽ xuất hiện tám khả năng xẩy ra sau đây: (1) - kích thước hạt trung bình nhỏ hơn, độ chọn lọc tốt hơn và độ bất đối xứng âm hơn; (2) - kích thước hạt trung bình lớn hơn, độ chọn lọc kém hơn và độ bất đối xứng dương hơn; (3) - kích thước hạt trung bình lớn hơn, độ chọn lọc tốt hơn và độ bất đối xứng âm hơn; (4) - kích thước hạt trung bình nhỏ hơn, độ chọn lọc kém hơn và độ bất đối xứng âm hơn; (5) - kích thước hạt trung bình lớn hơn, độ chọn lọc kém hơn và độ bất đối xứng âm hơn; (6) - kích thước hạt trung bình nhỏ hơn, độ chọn lọc tốt hơn và độ bất đối xứng dương hơn; (7) - kích thước hạt trung bình lớn hơn, độ chọn lọc tốt hơn và độ bất đối xứng dương hơn; (8) - kích thước hạt trung bình nhỏ hơn, độ chọn lọc kém hơn và độ bất đối xứng dương hơn. Mclaren and Bowles [8] đã sử dụng phương pháp toán học của Friedman để tính toán các thông số độ hạt trầm tích nên giá trị độ bất đối xứng có thể dương hoặc âm. Cũng theo McLaren and Bowles, chỉ có hai trường hợp $B$ và $C$ tương ứng với khả năng (1) và (7) là xẩy ra trên thực tế với xác suất $p=0.125$ bởi các trầm tích di chuyển xa nguồn cung cấp bao giờ cũng có độ chọn lọc tốt hơn các trầm tích ở gần nguồn cung cấp. Để xác định xem số lần xẩy ra một trong các trường hợp trên với xác suất là 0.125 , chúng ta sẽ phải kiểm tra hai hiện tượng sau đây:

$H_{0}: p \leq 0.125$, không xác định được xu hướng di chuyển trầm tích.

$H_{1}: p>0.125$, có xác định được xu hướng di chuyển trầm tích.

Áp dụng bài kiểm tra $Z$ - score của Spiegel [11], $H_{1}$ được chấp nhận nếu:

$Z=\frac{x-N p}{\sqrt{N q}}>1.645$ với mức ý nghĩa 0.05 ( 0.05 level of significance).

hoặc $Z>2.33$ với mức ý nghĩa 0.01 . 
trong đó: $x$ là số cặp mẫu ghi nhận một trong hai hướng đã được đề nghị, $N$ là tổng số cặp mẫu với $N=\left(n^{2}-n\right) / 2, n$ là số mẫu trầm tích, $p=0.125$ và $q=1-p=0.875$.

Bài kiểm tra $Z-$ score sẽ chỉ hợp lệ nếu $N \geq 30$. Vì vậy, để áp dụng phương pháp này, chúng ta phải có tối thiểu tám hoặc chín mẫu trầm trầm tích theo một tuyến mặt cắt nhất định để xác định xu hướng di chuyển trầm tích, ví dụ, $\left(9^{2}-9\right) / 2=36$ là tổng số cặp mẫu trầm tích theo một hướng.

\section{CHƯƠNG TRÌNH MÁY TÍNH XÁC ĐỊNH XU HƯớNG DI CHUYỂN TRÀM TÍCH}

Bài báo này ghi nhận chương máy tính ASTD (Analysis of Sediment Transport Direction) sử dụng phương pháp McLaren and Bowles dùng để xác định xu hướng di chuyển trầm tích. Chương trình sử dụng các thông số kích thước hạt trầm tích như đường kính hạt trung bình, độ chọn lọc và độ bất đối xứng được tính theo phương pháp Friedman để xác định xu hướng di chuyển trầm tích. Chương trình này được viết và biên dịch trên ngôn ngữ lập trình Compaq Visual Fortran Professional Edition 6.6.0 có thể chạy trên các máy tính sử dụng hệ điều hành Microsoft Window. Các máy tính sử dụng hệ điều hành khác như Macintosh, Linux, Unix có cài ngôn ngữ lập trình Fortran cũng có thể chạy được chương trình nói trên thông qua mã nguồn của nó. Định dạng đầu vào và đầu ra của chương trình được thiết kế rất đơn giản, dễ hiểu đối với cả những người ít kinh nghiệm sử dụng máy tính. Chương trình này có nhiều ưu điểm bởi nó chạy rất nhanh, dễ sử dụng, cho phép xác định xu hướng di chuyển trầm tích đã diễn ra trong qua khứ ở một vùng nhất định và đặc biệt, cũng rất hữu ích trong nghiên cứu đặc điểm chế độ thạch - động lực trầm tích cổ và hiện đại.

Toàn bộ quy trình tính toán của chương trình máy tính ASTD xác định xu hướng di chuyển trầm tích được trình bày ở hình 1 . Lúc bắt đầu mỗi chu trình tính toán, người sử dụng được yêu cầu đưa tên file đầu vào và thư mục chứa chúng. Tất cả dữ liệu đầu vào đều được chương trình kiểm tra xem có đúng định dạng của chương trình hay không, nếu có lỗi thì chương trình sẽ thông báo và yêu cầu nhập lại chúng. Sau khi đọc xong dữ liệu đầu vào đã thỏa mãn yêu cầu của chương trình, chương trình sẽ lập tức trả lại kết quả ngay sau đó trên màn hình MS Dos và file kết quả kèm theo.

Đầu vào của chương trình phải được định dạng theo ASCII TEXT. File đầu vào phải được tạo ra trước khi chạy chương trình. Toàn bộ dữ liệu đầu vào cần thiết cho chương trình tính toán bao gồm số mẫu trầm tích dùng để xác định xu hướng di chuyển trầm tích và các giá trị kích thước hạt trầm tích như kích thước hạt trung bình, độ chọn lọc và độ bất 
đối xứng. Trong khi sử dụng chương trình, cần phải chú ý rằng phương pháp McLaren and Bowles [8] sử dụng tối thiểu tám mẫu trầm tích theo một mặt cắt nhất định để xác định xu hướng di chuyển trầm tích. Nếu không cung cấp đủ tám mẫu theo một mặt cắt nhất định cắt để phân tích thì chương trình sẽ báo lỗi đầu vào. Phương pháp McLaren and Bowles [8] sử dụng thang cấp hạt $\emptyset$ với $\emptyset=-\log _{2} d$ ( $d$ là đường kính hạt được tính theo đơn vị milimetres) nên các thuật toán của chương trình cũng được thiết lập theo hệ đơn vị $\emptyset$. Vì vậy, chương trình ASTD cũng sẽ chỉ sử dụng các giá trị kích thước hạt trung bình, độ chọn lọc và độ bất đối xứng được tính theo phương pháp Friedman trên thang cấp hạt $\emptyset$.

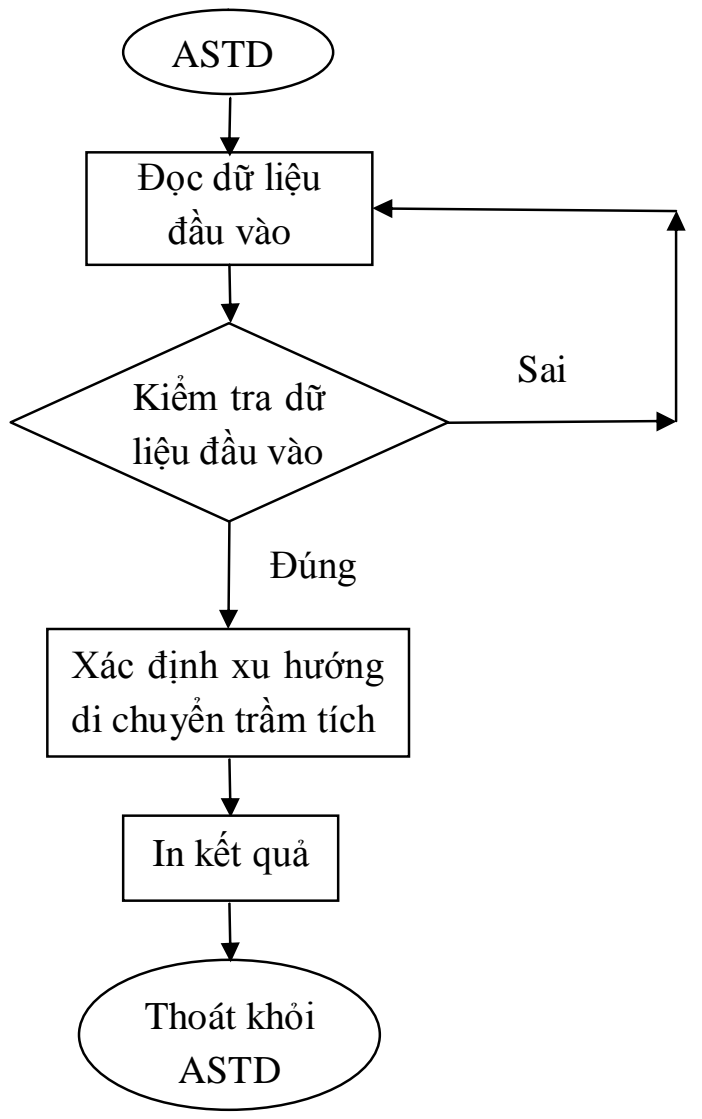

Hình 1: Sơ đồ khối của chương trình máy tính ASTD xác định xu hướng di chuyển trầm tích

Đầu ra của chương trình được thể hiện trên màn hình MS Dos và file kết quả kèm theo nằm ở thư mục chứa chương trình. Các thông tin chính về kết quả gồm số cặp mẫu 
theo mỗi hướng của mặt cắt và giá trị $Z$ - score đánh giá khả năng xẩy ra di chuyển trầm tích theo mỗi hướng nhất định của mặt cắt.

Nhằm kiểm tra chất lượng của chương trính máy tính xác định xu hướng di chuyển trầm tích ASTD, các ví dụ cụ thể trong bài báo của McLaren and Bowles [8] đã được thiết lập để kiểm tra và kết quả cho thấy chương trình ASTD tính toán chính xác.

\section{IV. ÁP DỤNG THỬ NGHIÊMM Ở VÙNG BIỂN VEN BỜ HẢI PHÒNG - QUẢNG NINH}

Để minh họa chương trình máy tính ASTD xác định xu hướng di chuyển trầm tích, hai mặt cắt ở vùng biển nông ven bờ Hải Phòng - Quảng Ninh (hình 2 và 3 ) đã được lựa chọn để sử dụng. Mặt cắt thứ nhất bao gồm 10 mẫu trầm tích thu ở khu vực vịnh Bái Tử Long nằm theo phương Đông Bắc - Tây Nam song song với phương cấu trúc của vịnh (bảng 1). Mặt cắt thứ hai bao gồm 21 mẫu trầm tích nằm ở phía ngoài vùng biển Bái Tử Long, Hạ Long và quần đảo Cát Bà cũng có phương Đông Bắc - Tây Nam (bảng 2). Kết quả của chương trình máy tính đã được chỉ ra ở bảng 3 và bảng 4 .

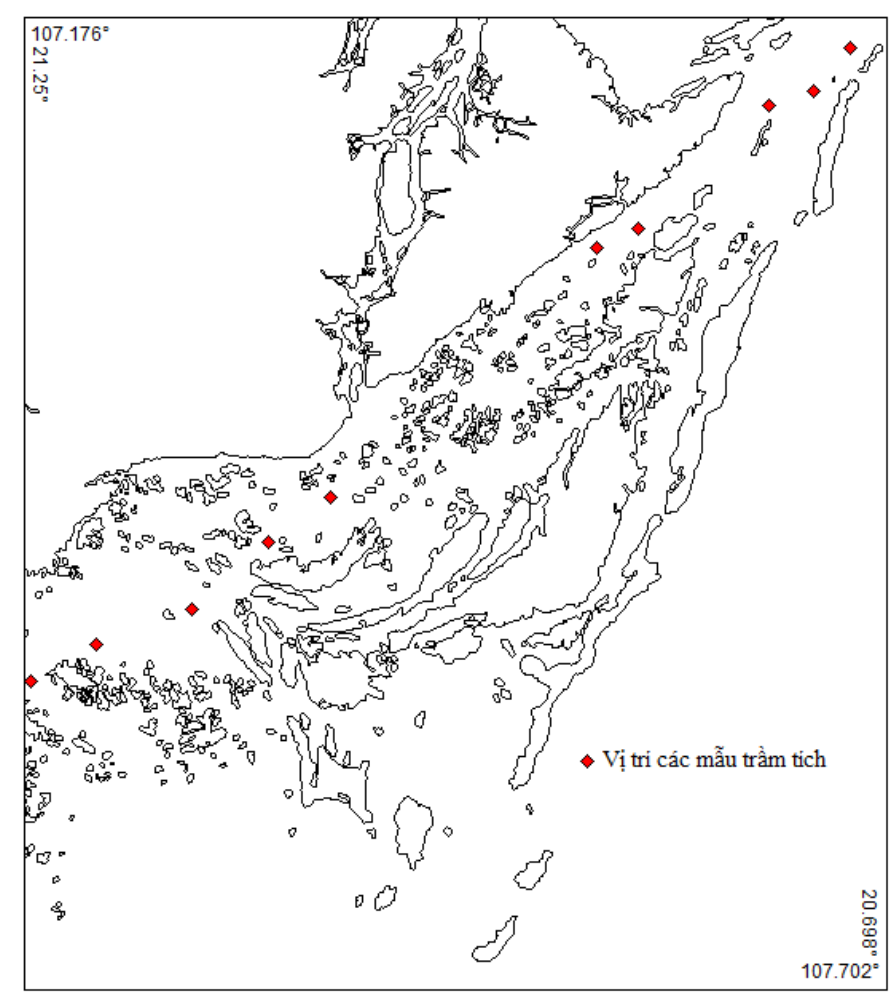

Hình 2. Vị trí các trạm thu mẫu trong khu vực Bái Tử Long 


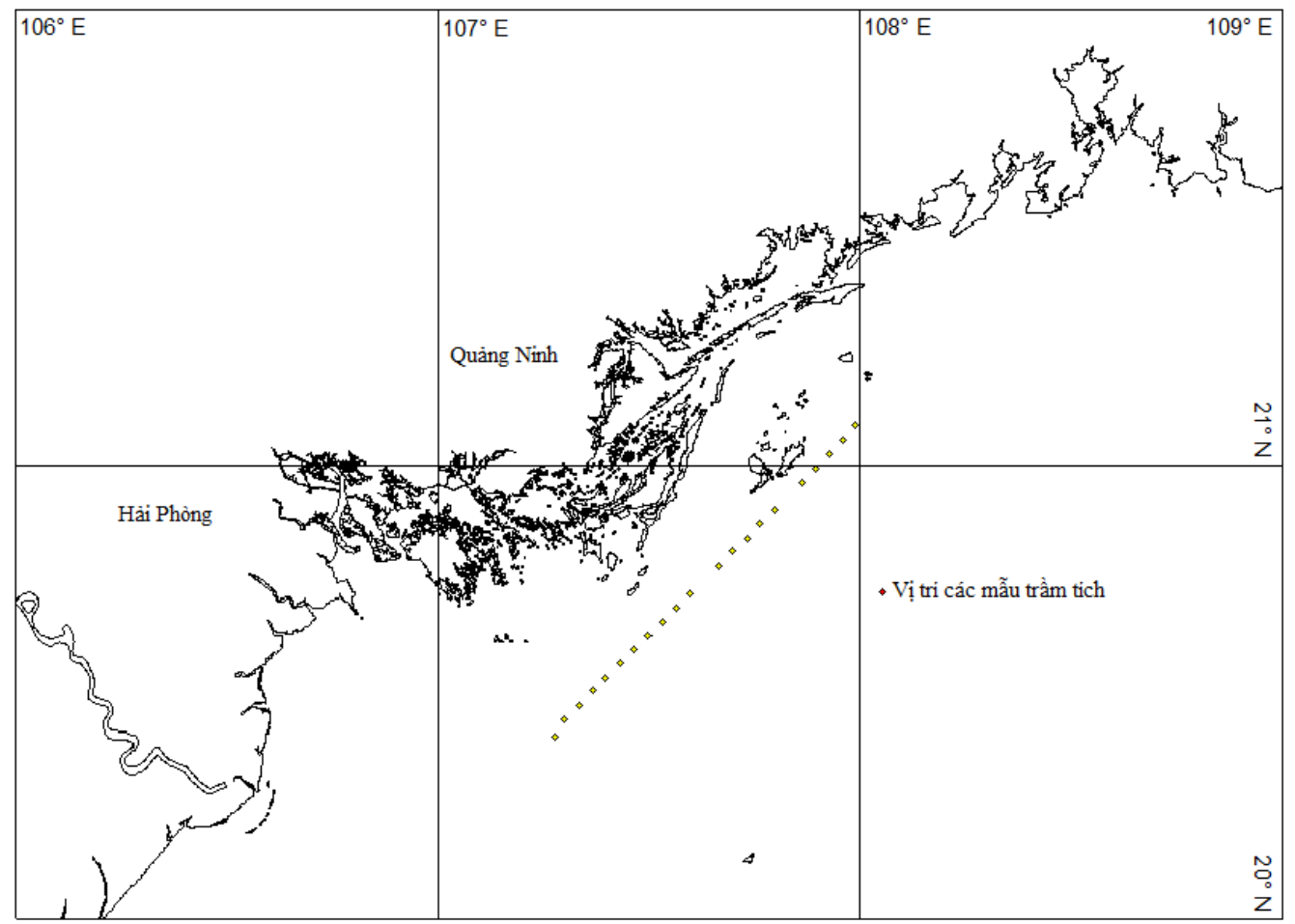

Hình 3: Vị trí các trạm thu mẫu trong khu vực Bái Tử Long - Hạ Long - Cát Bà

Bảng 1: Các thông số thống kê kích thước hạt trầm tích khu vực vịnh Bái Tử Long

\begin{tabular}{|c|c|c|c|}
\hline Ký hiệu mẫu & $\begin{array}{c}\text { Kích thước hạt } \\
\text { trung bình }\end{array}$ & Độ chọn lọc & Độ bất đối xứng \\
\hline 1 & 2.99023 & 0.61186 & -0.04517 \\
\hline 2 & 1.78456 & 0.73394 & -0.88821 \\
\hline 3 & 0.56948 & 1.50819 & -0.475 \\
\hline 4 & 0.63053 & 1.93114 & 0.47465 \\
\hline 5 & 1.00753 & 2.04531 & -0.27672 \\
\hline 6 & 2.90833 & 0.64795 & 0.15414 \\
\hline 7 & 2.91006 & 0.6384 & 0.08351 \\
\hline 8 & 3.36978 & 0.33038 & 0.4617 \\
\hline 9 & 3.44025 & 0.34751 & 0.57751 \\
\hline 10 & 3.48504 & 0.76718 & -1.51472 \\
\hline
\end{tabular}


Bảng 2: Các thông số thống kê kích thước hạt trầm tích cho khu vực phía ngoài vùng biển Hạ Long, Bái Tử Long và quần đảo Cát Bà

\begin{tabular}{|c|c|c|c|}
\hline Ký hiệu mẫu & $\begin{array}{c}\text { Kích thước hạt } \\
\text { trung bình }\end{array}$ & Độ chọn lọc & Độ bất đối xứng \\
\hline 1 & 2.62482 & 1.03297 & -1.39273 \\
\hline 2 & 2.6548 & 0.71705 & -0.84707 \\
\hline 3 & 3.53474 & 0.48026 & -1.25112 \\
\hline 4 & 1.958 & 1.25518 & -0.44953 \\
\hline 5 & 4.36039 & 2.09874 & -1.00877 \\
\hline 6 & 2.44233 & 0.73345 & -0.9253 \\
\hline 7 & 2.89309 & 0.59716 & -0.46371 \\
\hline 8 & 2.86764 & 0.56356 & -0.65366 \\
\hline 9 & 2.82891 & 0.49792 & -0.52937 \\
\hline 10 & 2.94683 & 0.55648 & 0.76441 \\
\hline 11 & 2.80883 & 0.56306 & -0.22253 \\
\hline 12 & 2.9011 & 0.53008 & 0.11771 \\
\hline 13 & 1.59441 & 1.34157 & -0.36979 \\
\hline 14 & 3.30693 & 0.46996 & 0.84921 \\
\hline 15 & 3.25781 & 0.5142 & -0.19262 \\
\hline 16 & 3.34198 & 0.48954 & -0.40209 \\
\hline 17 & 2.72141 & 0.48667 & -0.0422 \\
\hline 18 & 2.63437 & 0.48033 & -0.12131 \\
\hline 19 & 3.21907 & 0.4536 & -0.7822 \\
\hline 20 & 1.60623 & 1.87898 & -0.95759 \\
\hline 21 & 2.27366 & 0.29716 & -0.56349 \\
\hline
\end{tabular}

Kết quả chạy từ chương trình máy tính cho thấy rằng ở vịnh Bái Tử Long (bảng 3) trầm tích không có xu hướng di chuyển theo hướng Đông Bắc hoặc Tây Nam. Điều này chỉ xảy ra khi các trầm tích được thành tạo có nguồn gốc từ các đảo trong vịnh tích tụ ngay gần đó mà không di chuyển ra xa nguồn cung cấp, tức là trong trường hợp này không 
phản ánh rõ ràng xu thế di chuyển trầm tích về phía Đông Bắc hoặc Tây Nam. Thật vậy, khu vực vịnh Bái Tử Long có độ sâu không lớn và độ muối cao nên sự phân tầng chất rắn lơ lửng trong khu vực này không nhiều [12]. Hơn nữa, hàm lượng chất rắn lơ lửng trong vịnh Bái Tử Long rất thấp (nhỏ hơn $25 \mathrm{mg} / \mathrm{l}$ ), chứng tỏ rằng trầm tích ít di chuyển trong vịnh Bái Tử Long. Do cách tiếp cận của phương pháp McLaren and Bowles được xây dựng trên nguyên lý "trầm tích di chuyển xa nguồn cung cấp luôn có độ chọn lọc tốt hơn so với ở gần nguồn cung cấp trầm tích" nên kết luận của chương trình máy tính cho vịnh Bái Tử Long là hợp lý.

Bảng 3: Kết quả xác định xu hướng di chuyển trầm tích cho vịnh Bái Tử Long

\begin{tabular}{|c|c|c|}
\hline $\begin{array}{c}\text { Các trường họ̣p di } \\
\text { chuyển trầm tích }\end{array}$ & Hướng Đông Bắc & Hướng Tây Nam \\
\hline \multirow{2}{*}{ Trường hợp $\mathrm{B}$} & $\mathrm{X}=6$ & $\mathrm{X}=7$ \\
\cline { 2 - 3 } & $\mathrm{Z}=0.1690308$ & $\mathrm{Z}=0.6197798$ \\
\hline \multirow{2}{*}{ Trường hơp C } & $\mathrm{X}=7$ & $\mathrm{X}=0$ \\
\cline { 2 - 3 } & $\mathrm{Z}=0.6197798$ & $\mathrm{Z}=-2.535463$ \\
\hline
\end{tabular}

Bảng 4: Kết quả xác định hướng di chuyển trầm tích cho khu vực phía ngoài vùng biển Bái Tử Long, Hạ Long và quần đảo Cát Bà

\begin{tabular}{|c|c|c|}
\hline $\begin{array}{c}\text { Các trường họ̣p di } \\
\text { chuyển trầm tích }\end{array}$ & Hướng Đông Bắc & Hướng Tây Nam \\
\hline \multirow{2}{*}{ Trường hợp $\mathrm{B}$} & $\mathrm{X}=25$ & $\mathrm{X}=24$ \\
\cline { 2 - 3 } & $\mathrm{Z}=-0.2608203$ & $\mathrm{Z}=-0.4694765$ \\
\hline \multirow{2}{*}{ Trường hơp C } & $\mathrm{X}=4$ & $\mathrm{X}=41$ \\
\cline { 2 - 3 } & $\mathrm{Z}=-4.642601$ & $\mathrm{Z}=3.077679 *$ \\
\hline
\end{tabular}

* Mức ý nghĩa 0.01

Đối với mặt cắt thứ hai ở phía ngoài vùng biển Bái Tử Long, Hạ Long và quần đảo Cát Bà, kết quả chạy từ chương trình máy tính (bảng 4) chỉ ra rằng trầm tích có xu hướng di chuyển về phía Tây Nam. Các nghiên cứu khác ở khu vực vịnh Bắc bộ cũng đã chỉ ra rằng có sự tồn tại trong cả năm của dòng chảy ven bờ Tây vịnh Bắc bộ theo chiều từ Bắc xuống Nam $[1,14]$. Bên cạnh các nghiên cứu trên, nghiên cứu của Lê Xuân Hồng và các cộng sự [5] cũng chỉ ra rằng dòng bùn cát của sông Hồng có xu thế di chuyển về phía Nam. Điều đó chứng tỏ mô hình McLaren and Bowles cho kết quả rất tốt bởi xu hướng di 
chuyển dòng trầm tích luôn phụ thuộc vào hướng của dòng chảy ven bờ Tây vịnh Bắc bộ.

\section{KẾT LUẬN}

Chương trình máy tính ASTD (Analysis of Sediment Transport Direction) được viết trên ngôn ngữ lập trình Fortran, dựa trên phương pháp của McLaren and Bowles [8], cho phép xác định xu hướng di chuyển trầm tích. Chương trình sử dụng dữ liệu đầu vào là các giá trị đường kính hạt trung bình, độ chọn lọc và độ bất đối xứng của các trạm thu mẫu trầm tích theo những tuyến mặt cắt nhất định. Chương trình ASTD cho phép tính toán rất nhanh và kết quả của nó có ý nghĩa rất quan trọng trong nghiên cứu trầm tích luận, đặc biệt là luận giải chế độ thạch động lực của môi trường tích tụ trầm tích. Các kết quả kiểm tra cho thấy chương trình ASTD luận giải đúng đặc điểm chế độ thạch động lực của vùng biển nông ven bờ Hải Phòng - Quảng Ninh thông qua hai mặt cắt được lựa chọn ở khu vực vịnh Bái Tử Long và khu vực phía ngoài vịnh Bái Tử Long, Hạ Long và quần đảo Cát Bà.

\section{TÀI LIỆU THAM KHẢO}

1. Báo cáo điều tra tổng hợp vịnh Bắc bộ, phần thứ 2 , Vật lý thủy văn, 1964. Lưu trữ tại Viện Tài nguyên và Môi trường biển, Hải Phòng.

2. Ehrlich, R. and Davies, D.K., 1968. Sedimentological indices of transport direction, distance, and process intensity in glacio-fluvial sediments. Journal of Sedimentary Petrology, Vol. 38, No. 4, p. 1166 - 1170.

3. Gao, S. and Collins, M., 1991. A critique of the "McLaren method" for defining sediment transport paths - discussion. Journal of Sedimentary Petrology, Vol. 61, No. 1, p. 143 - 146.

4. Gao, S. and Collins, M., 1992. Net sediment transport patterns inferred from grain size trends based upon definition of "transport vectors". Sedimentary Geology, 80, p. 47 - 60.

5. Lê Xuân Hồng, Lê Xuân Hoàn và Nguyễn Thị Kiều Duyên, 2005. Vận chuyển bùn cát sông Hồng dọc ven bờ biển vịnh Bắc bộ trên cơ sở phân tích khoáng vật nặng. Tạp chí Khoa học ĐHQGHN, KHTN \& CN, tập XXI, số 3, trang 30 - 39.

6. McCave, I.N., 1978. Grain size trends and transport along beaches: an example from eastern England. Marine Geology, v. 28, No. 1-2, p. 43 - 51.

7. McLaren, P., 1981. An interpretation of trends in grain size measures. Journal of Sedimentary Petrology, Vol. 51, No. 2, p. 611 - 624. 
8. McLaren, P. and Bowles, D., 1985. The effects of sediment transport on grain size distributions. Journal of Sedimentary Petrology, Vol., 55, No. 4, p. 457 - 470.

9. Pettijohn, F.G., and Ridge, J.D., 1932. A textural variation series of beach sands from Cedar Point, Ohio. Journal of Sedimentary Petrology, Vol. 2, No. 2., p. 76 - 88.

10. Russell, R.D., 1939. Effects of transportation of sedimentary particles. In: Trask, P.D. (ed.), Recent marine sediments: Society of economic paleontologists and mineralogists, Tussa, Oklahoma, p. $32-47$.

11. Spiegel, R, M., 1998. Theory of Problems of Statistics: Schaum's Outline Series, New York, McGraw-Hill Book Co., 23 rd printing, 376 p.

12. Trần Anh Tú, Đỗ Đình Chiến, Vũ Duy Vĩnh, Trần Đức Thạnh và Nguyễn Thị Kim Anh, 2009. Mô phỏng lan truyền chất ô nhiễm môi trường nước vùng vịnh Hạ Long Bái Tử Long. Tuyển Tập Tài nguyên và Môi trường biển, Tập XIV, trang 271 - 280.

13. Vanwesenbeeck, V. and Lanckbeus, J., 2000. Residual sediment transport paths on a tidal sand bank: a comparison between the modified McLaren model and bedform analysis. Journal of Sedimentary Petrology, Vol. 70, No.32., p. 470 - 477.

14. Wyrtki, K., 1961. Scientific results of marine investigations of the South China Sea and gulf of Thailand 1959 - 1961. The University of California, California.

COMPUTER PROGRAM FOR ANALYZING SEDIMENT TRANSPORT

DIRECTION: APPLICATION TO THE HAI PHONG - QUANG NINH COASTAL MARINE AREA

\title{
NGUYEN NGOC ANH, NGUYEN VAN VUONG
}

\begin{abstract}
Summary: Grain size parameters change in different sedimentary environments such as rivers, beaches, deserts and etc. However, spatial variations in the parameters also exist within the same environment, in response to sediment transport direction. McLaren and Bowles pointed out that the grain size parameters may be used to deternamite sediment transport direction. This study presents a fortran program for analyzing sediment transport direction, using the method decribed by McLaren and Bowles. It is written in Compaq Visual Fortran Professional Edison 6.6.0 and can run within Window computers. Calculated results from the program can be helpful in sedimentological studies, especially for the reconstruction of litho-dynamical environments.
\end{abstract}

Ngày nhận bài: 05 - 7 - 2011

Người nhận xét: PGS. TS. Trần Đức Thạnh 